\title{
DINI TEMALI RADIKALIZM VE TÜRK CUMHURIYETLERI
}

\author{
- Religious Themed Radicalism and Turkish Republics -
}

\section{Prof. Dr. Ramazan BİÇER}

Sakarya Üniversitesi İlahiyat Fakültesi

\begin{abstract}
The radical religious movements that originated in the Middle East started activities intensely after the independence of the Central Asian Turkish Republics. Taking advantage of the religious vacuum after the collapse of the USSR for their radical religious movements in this area, these movements propagated radical Islam in the Central Asia and Balkans, where Muslim Turks are in majority and have traditional Hanafi-Maturidit understanding of Islam. However, the Salafi-Wahhabi understanding of Islam with radical philosophy based on Kharijite understanding and containing violence disturbed people. This situation has led to experiencing serious problems.

Key words: Religion, Radicalism, Kharijite, Salafi-Wahhabi, Turkish Republics.
\end{abstract}

\section{Giriş}

Dinler insanların mutluluğunu hedeflemektedir. $\mathrm{Bu}$ ise, dünya hayatındaki iyi ve dürüst yaşamlarının, bir sonraki hayatta ödüllendirileceği şeklinde ifade edilmektedir. Buradaki temel değerlendirme, inanan kimselerin dini buyrukları uygulamasına yöneliktir. Herhangi bir dine mensup olup da, onun vecibelerini yerine getirebilenler, dini açıdan iyi yani dindar kimselerdir. Birçok inanan, dine aidiyetini ileri sürmekle birlikte, onun buyruklarına göre hareket etmemektedir.

Dini karşısında insanlar genelde üç tutum içerisindedirler. İlki, inanç ve kabul boyutunda bir dini benimsemekle birlikte, seküler veya agnostik bir anlayışın sonucu, uygulamada ilgisiz kalmaktadır. İkincisi ise, mensubu olduğu dini özellikle sosyal ve geleneksel yapısı doğrultusunda, halk Müslümanlığ 1 olarak nitelendirilen bir tutum içerisindedirler. Üçüncüsü ise, dininin kurallarını, genel geçer anlayışın ötesinde algılayarak, farklı ve kendi anlayışına göre daha gerçekçi bir dini hayata sahip olduğuna inanarak, inananların genelinin anlayışının dışında bir uygulamaya sahip olmaktır (Uysal 1996: 134-137). 
$\mathrm{Bu}$ kategoride olanlar bazen radikal bazen de marjinal olarak nitelendirilmektedir. Böyle bir algılama ise, ya dinin özüne yönelik bir derinliğe sahip olmakla olur, ya da din adına konuşarak, kendi kültür, bilgi seviyesi ve algılama biçimi doğrultusunda dini sunum yapan belli kimselerin yönlendirmesiyle gerçekleşir. Dini bilincin doruğuna tırmanarak ilk kategoriye giren insanlar çok azınlıkta olmuştur. İnananların çoğu ikinci oluşum içerisindedir. Buradaki ana etken, yönlendiren kimsenin dini algılama ve sunum biçimidir. Bu nedenle ikinci kategori, olumlu veya olumsuz ciddi sonuçlar verebilir. Orta Asya Türk dünyasının Müslümanlaşmasındaki büyük rolü olan Yesevilik gibi tasavvuf hareketlerinin katkısı ile günümüzde aynı bölgede sorun oluşturan radikal hareketlerin yönlendirici liderlerin anlayışı buna bir örnektir (Biçer 2009b).

Her halükarda din belli bir anlayış veya algılamalar doğrultusunda zorunlu olarak şekillendirilemez. Yani din belli bir kimse, kitle ve oluşumun tekelinde değildir. Farklı kesim ve dönemlerde, ana gövdeye zarar vermemek ve genel geçer temelleri yıpratmamak şartıyla, farklı biçimlerde algılanabilir ve sunumu yapılabilir. Hatta dinin özüyle hiç de alakası olmayan ama ona nispet edilen dini anlayışlar da çıkabilir. Birçok mezhep ve tarikatların ortaya çıkması, bu tezin referanslarıdır. Bu sonuç hem sosyolojik hem de dinin amacı itibarıyla doğaldır. Zira birçok mezhep, dinin özüne yönelik okuma biçiminden doğmuştur. Mevlana'nın meşhur fil benzetmesinde olduğu gibi, dini oluşum ve gruplar, o dinin belli bir boyutunun söylemini oluşturmuşlardır.

Bir dini akım ve oluşum hakkında doğru veya yanlış hükmünü vermek iki şekilde mümkündür: Birincisi, bir başka dinin verileri doğrultusunda olur. İkincisi ise, bizzat o dinin kendi kaynaklarına göre doğrulama veya yanlışlama yapılabilir. Burada mesela İslamî bir mezhep hakkında bir değerlendirme yapılacak olursa bu, mensup olduğu dinin temel kaynakları açısından bir yaklaşımda bulunulabilir. Ancak burada karşımıza çıkan bir başka problem ise, her grubun ve kesimin kendi inancının, öze daha yatkın ve uygun olduğu tezidir. Hatta Müslümanların genelinin kabulüne mazhar olmamış ve radikallikle suçlanmış bazı hareketler, kendilerini dinin kaynaklarına daha uygun olarak nitelendirmektedirler. Nitekim bugün bazı terör eylemlerine katılan kimselerin, dinin özünü dönüş hareketi olarak adlandırılan Selefi-Vehhabi felsefesini benimsedikleri bilinmektedir (Ebu Zehra 1997: 264-266).

İslam tarihinde ortaya çıkan kelam ve akaid alanındaki mezhepler, Şiilik, Mu’tezile, Haricilik ve Ehl-i Sünnet adları etrafinda şekillenmiştir. Mu’tezile mezhebi, İmamiyye konusu dışında ana hatlarıyla Şiilik mezhebinin temel felsefesi olmuştur. Güçlü dönemler yaşamış, İslam düşüncesine önemli katkıları bulunmuş olan Mu’tezile mezhebinin günümüzde resmi temsilcisi konumunda geniş çaplı bir oluşum bulunmamaktadır. Şiilik, İslam dünyasının azımsanmayacak bir kesiminin 
mezhebi olmuş, yüzyıllardır inanç sistemini geliştirmiş, Mu'tezile-felsefe destekli güçlü bir teolojiye sahip olmuştur (Topaloğlu, 2004: 143-145).

Kendisine özgü bir felsefesi bulunmakla birlikte, baştan beri İslam dünyasında radikal çıkışlar yapan, dinin uygulama boyutuna daha çok önem verdiği için sürekli aksiyon içerisinde olan, cumhurun egemenliğinin hakim olduğu, çıkış yerinin lokal şartlarını da yansıtmak suretiyle daha çok yerel bir anlayışa sahip olan Haricilik, önemli görüşlerini Vehhabilik mezhebi çerçevesinde devam ettirmektedir. (Büyükkara 2004: 157-1169).

İslam dünyasında yaygın bir konuma sahip olmuş, Mu’tezile ve Şia arasında bir inanç sistemini benimsemiş olan Ehl-i sünnet, belirli kalıplara sokulmuş kurallardan daha çok, dinin uygulanmasını hedeflemiş ve bu şekilde dinin ana teması içerisinde geniş açılımlı bir itikat/inanç yelpazesine sahip olmuş, evrensel değerler doğrultusunda İslam'ı yorumlamış ve böylece insan öncelikli, yaşanabilir nitelikli bir dinî anlayışı benimsemiştir (Emin 1954: 125).

$\mathrm{Bu}$ veriler çerçevesinde her İslam Okulu, Müslümanlığı kendi okuma biçimi doğrultusunda değerlendirdiğinden, 'doğru' ve 'gerçek' İslam'ın kendi algıladığı şekliyle olduğunu benimsemiştir. Bu ekollerin yüzyıllardan varlığını sürdürmesinin temelinde bu kavrayış bulunmaktadır. O nedenle tarihsel süreçte yerleşik düzene geçmiş mezheplerin biteceğini düşünmek mümkün değildir. Zorlandıkları zaman sadece gizlenirler.

İslami inanç mezhepleri, temel felsefelerini Kur'an'dan almışlardır. Bu nedenle hepsinin haklı gerekçeleri bulunmaktadır. Buradaki ölçü, gerekçelerin realiteyi yansıtma oranı ve geçerlilik boyutudur. Buna göre radikal bir mezhep olarak değerlendirilen Haricilik, Kur'an'a dayanan söylemlerde bulunmakla birlikte, bunların kullanım yeri ve bağlamı tartışılabilir (Biçer 2009: 940-942).

Kur'an'a yapilan bir başvurunun tutarlılı̆ıının iki temel unsuru bulunmaktadır. Kur'an'ın dili olan Arapça kuralları çerçevesinde oluşan bir anlayış ve yorum yanında, çıkarılan hüküm ve ulaşılan kanaat, Kur'an'ın ana teması ve genel fikri etrafında oluşmalıdır. Bu bağlamda mesela İsmaililik gibi bazı aşırı firkaların Kur'an okuma biçimi, her iki değerlendirmenin dışında olmuştur.

Öte yandan Kur'an merkezli bir anlayışa sahip olduğunu ileri süren Haricilik ve daha sonraki oluşum olan Vehhabiliğin, hedef kitle olarak daha çok Müslümanları seçmesi Kur'an'ın ana temasıyla bağdaşmamaktadır. Haricilik-Vehhabilik bağlantısı çok belirgindir. Nitekim Osmanlı tarihinde Vehhabilige "Hâricilik" hareketi olarak bakılmış ve o şekilde isimlendirilmiştir. Davranışlarındaki sertlik, iman ölçütlerindeki taassup ve kendi dinî inanışlarında olmayanları küfür ve şirkle suçlamak gibi hususlarda 
Vehhabilik ile Hâricilik arasında belirgin bir benzerlik vardır. Haricilerin günümüzde yasayan kolu İbâdiyye, el-Emru bi'l-Ma'ruf ve'n-Nehyu ani'l-Munker'i Munker'i (iyiliği emredip kötülüğü yasaklama) İslâm'a davet adı altında Müslümanlarla savaşmak seklinde ele almışlar ve bu görüşleriyle Vehhabilere örnek teşkil etmişlerdir (Fığlalı 1999: 125).

Haricilik, İslam dünyasında şiddet ve uzlaşmacilığın ilk temsilcileri olmuştur. onların siyasî ve itikadî görüşleri hicri 64'lere doğru sistematik bir nitelik kazanmaya başlamıştır. Zira bu dönemde onlar, Ezârıka, Necedât, İbâdiye ve Sufriyye gibi firkalara ayrılmaya başlamışlardı. Bu tarihler aynı zamanda Haricilerin merkezden, Kirman, Horasan gibi yerlere yayılma zamanıdır (Yönem 2005: 10).

Hariciler, merkezi yönetime uzak olan ve dolayısıyla siyasî otorite boşluğu bulunan, Horasan-Maveraünnehir bölgesine yerleşmişlerdir. Onlar Kirman darphanesini kullanarak belli dönemlerde kendi adlarına para bile bastırmışlardır. Hariciler, bir süre sonra bölgedeki etkinliklerini tamamen kaybetmişlerdir. Ancak onların zihniyeti bölgede kalıntılarını bırakmışlardır (Yönem 2005: 11).

Vehhabiliğin temel dayană̆ , Selef akidesidir. Bu nedenle kendilerini Selefi olarak tanımlarlar. Günümüz edebiyatında terör ve radikal eylemlere katılanlar da Selefi-Vehhabi şeklinde değerlendirilmektedir (Biçer 2006: 275).

Selefilik geniş kapsamlı ve karmaşık bir kavramdır. Ne zaman başladığı bilinmediği gibi, temsilcilerinin kimler olduğu da tam olarak tarif edilememektedir. Selef olarak nitelendirilen bazı kimseler, günümüz Selefi düşüncesi ile bağdaşmamaktadır. Bu akım genellikle Vehhabi hareketiyle bağdaştırılmakta ve günümüzde de bu akım mensuplarına Selefi-Vehhabi denmektedir (Wiktorowicz 2006: 207-208). Bununla birlikte onlar kendilerini "Ehl-i Sünnet-i Hassa" şeklinde tanımlamaktadırlar.

Selef, önceki, geçen anlamında olup, Selefi de öncekileri takip eden, onların yolundan giden ve metotlarını benimseyen manasındadır. Önceliklerden maksat da, Hz. Peygamberin arkadaşları olan sahabe ve onlarla görüşen, artlarından gelen nesil demek olan tabiîn kastedilmektedir.

Selefiyye anlayışının en belirgin özelliği akaid sahasında akla rol vermemek, ayet ve hadisin düz manasıyla yetinmek, anlamı apaçık olmayan, bu sebeple de yorumlara açık olan ayet ve hadisleri te'vil etmeden, bunları bilmeyi Allah'a havale etmek şeklinde özetlenebilir.

Buna göre ilk Müslüman ekoller oluşmadan önceki geçiş döneminde yaşayan ve İslam inancı ile ilgili konularda konuşan kimseler, selef olarak kabul edilmektedir. Diğer bir ifadeyle Es'ârilik ve Maturîdilik ortaya çıkıncaya kadar, Sünnî Müslüman çevrede hâkim olan inanç, Selef inancıdır. Bu bağlamda İmam olarak nitelendirilen kimseler yani, Safîi, Mâlik, Ahmet b. Hanbel, Ebu Hanife, Evzâî, Servi gibi müçtehid imamlar; Buhârî, Müslim Ebu Davud, Dârimî, İbni 
Mende, İbn Kuteybe, ve Beyhakî gibi hadisçiler; Taberî, Hatib el-Bagdâdî, Tahavî, İbnü'l-Cevzî ve İbn Kudâme gibi düşünürler selef düşüncesinin önde gelen isimleri arasında sayılabilir (Topaloğlu 2004: 79).

Selefilik daha çok İbn Teymiyye ile farklı bir ivme kazanmış ve sistematik bir boyuta ulaşmıştır. Bu nedenle Selefilik dendiğinde genellikle İbn Teymiyye akla gelmektedir.

İbn Teymiyye'nin temel felsefesi, İslam dünyasının genişlemesi ve farklı kültürlerle diyaloga geçmesiyle birlikte, dinî anlayışa ilave edilmiş bid'at mahiyetindeki itikadî ve amelî konularda, yeni anlayış ve oluşumlardan dini arındırıp, onu sahabe zamanındaki ölçüler içinde ortaya koymak ve bir bütün olarak İslam dinini, ilk muhataplarının anladığı biçimde anlatmak ve anlamaktır.

İslam itikadı alanıyla ilgilenen kelamcılar, İslam tarihçileri ve İslam mezhepler tarihçileri, Haricîlik ve Vehhabilik felsefesi arasında ciddi bir yakınlık ve ilişki olduğu kanaatindedirler. Ayrıca Osmanlı dönemi tarihçileri yanında resmî yazışmalarda da bu ilişki önemle vurgulanmıştır (Ecer 1976). Buna rağmen Vehhâbiler kendilerine "Muvahhidûn" derler ve kendilerini İbn Teymiyye'nin açıkladığı şekilde Ahmet b. Hanbel'in mezhebini devam ettiren Sünnîler olarak görürler. Nitekim onlar, "Biz, itikatta Selef, amelde de Hanbelî mezhebindeniz. Esasen Ahmed b. Hanbel, itikad hususunda Selef mezhebinin nasc1 (eseriyye) kolunu temsil eder. Onun ameldeki yolu da budur. Binaenaleyh biz amelde ve itikatta Hanbelîyiz; Vehhâbî diye bir şey yoktur. Bu akımın müessisi olan Muhammed b. Abdülvehhâb, ilmen ve fiilen bu mezhebi yenileyen bir Seyhülislam'dan başka bir kimse değildir" şeklindedir (Fığlalı 1999: 105-106). Ancak Vehhabilerin, amelde ve itikatta tamamen Ahmet b. Hanbel ve İbn Teymiyye'nin doktrinini yansıttıkları söylenemez.

İbn Abdülvehhab'ın temel felsefesi, altı yüz yıldan beri insanların delalette kaldığı, Müslüman denilenlerin aslında müşrik olduklarını, bu sebepten dolayı malları ve canlarının helal olduğu ve isyan edilmesi gerektiği, bid'atın savaşılması gereken bir "münker" olduğu, 'iyiliği emretme kötülükten sakındırma" ilkesiyle hareket etmenin kendilerine ve tüm Müslümanlara vacip olduğu şeklindedir. Vahhâbiler, Kur'an ve Sünnet'in zahiri anlamının dışındaki her yeni algılayış biçimini bid'at saymışlar ve bid'at içinde olanlarla savaşmanın gerekli ve zaruri olduğuna inanmışlardır (Ebu Zehra 1993: 110-113). 


\section{Orta Asya Türk Cumhuriyetlerinde Radikal Dinî Akım Söylemlerinin Oluşum Etkenleri}

Sovyetler Birliğinin dağılmasından sonra Orta Asya'da birçok Türk Cumhuriyeti kurulmuş, bazıları da Rusya Federasyonu çatısı altında kalmıştır. 1991'li yıllarda kurulan Türk Cumhuriyetleri, bu yeni oluşumlarında birçok siyasî, kültürel ve dinî problemlerle karşı karşıya kalmışlardır.

Sovyetler Birliği öncesi bölgedeki Türk Cumhuriyetleri Hanefî Matüridî eksende bir dinî anlayışa sahiptiler. Komünist dönemde dinî bir çölleşme yaşayan ve ateizasyon hareketine maruz kalan Türkler, yeni cumhuriyet oluşumlarında dinî boşluğu iyice hissetmeye başlamışlardır. Bu boşluk iki şekilde doldurulmaya çalışılmıştır. İlki ABD başkanı G. Bush'un da vurguladığı gibi, Hıristiyan misyonerler bu alanlara akın etmiş ve başta Amerika olmak üzere Batı devletlerinin maddi ve psikolojik desteğini alan misyonerler, yoğun ve kapsamlı bir faaliyete girişmişlerdir (Keskin 1996: 161).

İkincisi ise, Orta Doğu kökenli radikal dinî-İslamî akım mensupları bu yörelere akın etmişlerdir. $\mathrm{Bu}$ daha çok Selefi-Vehhabi felsefe etrafında şekillenmiştir.

Orta Asya'da özellikle Türk devlet ve halklarının büyük çoğunluğu Müslümandır. Dolayısıyla Sovyetler Birliği'nin dağılmasından sonra, oluşan sosyal gelişmelerde din öncelikli bir yere sahip olmuştur. Komünist dönem sonrasında bazı kesimler dinden uzaklaşma temayülünde olmuşsa da, etnik geçmiş, gelenekler ve kültürel ortam, dinin varlığını korumuştur.

Bununla birlikte yeni dönemde dini sunumu üstlenen otoritelerin zayıflığı, halkın dinî bilgilere ulaşmadaki yoksunluğu ve başta ekonomik olarak yönetimlerin karşı karşıya kaldıkları problemlerin çözümünü yönelik adımlar atılırken, bir başka sosyal sorun olan dinin ihmal edilmesi gibi gerekçeler, dinî kültürel sahanın henüz yeterli seviyede işlenemediğini göstermektedir. Bu durumun bilincinde olan din diş etkenler de bu yörelerde bazen resmî, bazen de gayr-i resmî olarak faaliyetlerde at başı gitmektedirler (Helmich 2008).

Problem bu boyutuyla yeni değildir. Nitekim 18. Yüzylldan itibaren bu bölgeleri işgal eden Ruslar, Türk halklarının dinî yapısını bozmak, dolayısıyla işgale yönelik eylemleri kırmak amacıyla iki tür bir girişim içerisinde bulunmuştur. Bunlardan ilkini, Hıristiyanlaştırma çabaları oluştururken, ikincisi ise İslamî gelişmelere yönelik engeller oluşturmak şeklinde tezahür etmiştir. Günümüzde de benzer metotlar uygulanmaya devam edilmektedir. Özellikle yeni Türk devletlerinde kabaran dinî duyguların doğurduğu oluşum ve gelişmeler, dinî terör, radikalizm, Selefi-Vehhabi gelişme türü söylemlerle kıstırılmaya çalışılmaktadır (Erdem 2004: 80). Böylece dini duygulara sahip kesimler ya dışlanmakta ya da haksız bir şekilde şiddete maruz kalmaktadır. Her iki gelişme de radikalliğe yönlendirmektedir. 
Sorunun farklı bir boyutu da idarîdir. Şöyle ki, Yeni Türk Cumhuriyetlerindeki yönetimler, siyasî ve ekonomik başarısızlıklarını örtbas etmek, Batı toplumlarının sempatisini kazanmak, Sovyet döneminden kalma ve mübtelası oldukları tek parti anlayışını sürdürmek ve demokratik olmayan yöntemlerle elde tuttuğu iktidara muhalefet edenleri baskı altında tutmak amacıyla dinî söylemleri kullanmaktadırlar. Bu söylem, dinî savunmadan öte bir husustur. Bir anlamda ciddi bir potansiyele sahip olmayan radikal akımların mevcudiyetinden hareketle, siyasî iktidarını güçlendirmek amacı gütmektedir (Baycaun 2001: 97; Erşahin 186: 190).

Bir başka önemli etken de, Orta Asya'da dünya devleri olan Amerika ve Rusya'nın varlık mücadelesi karşısında küçük devletlerin üzerinde gerçekleştirilen satranç oyununda, din bir piyon olarak kullanılmasıdır. $\mathrm{Bu}$ bağlamda her iki güç de mevcut iktidarı destekleyerek onu kendi tarafına çekmek, onun karşısında olanları terör ve radikallikle suçlamak ve bu alanda ona yardım etmek amacıyla düşman yaratmak ve mevcut iktidarı korumak düşüncesi ardından kendi çıkarlarını korumak anlayış yatmaktadır (Davlatov 2006: 179).

Bütün bunların ötesinde Sovyetler Birliğinin yıkılışının ardından, Orta Doğu kökenli dini hareketler, Türk Cumhuriyetlerinde ciddi faaliyetlere başlamışlardır.

\section{Türk Cumhuriyetlerinde Dini Motifli Radikal Hareketler}

Orta Asya Türk Cumhuriyetlerinin maruz kaldığı radikal dinî akımlar iki kategoride ele alınabilir. Bunların birincisini, öncelikle Hıristiyanlık dinine ait olmak üzere misyonerlik faaliyetleri oluşturmaktadır. Ardından Budizm ağırlıklı olmakla birlikte senkretik bir yapıda olan ve Yeni Çağ Dini akımlar olarak nitelendirilen oluşumlar teşkil etmektedir.

İkinci kategoriyi İslamî, dinî oluşumlar şekillendirmektedir. Orta Asya Türk Cumhuriyetlerinin maruz kaldığı radikal dinî akımların bir boyutunu Şî̂lik oluşturmaktadır. Tacikistan yanında Sovyetler Birliği sonrası Orta Asya Türk Cumhuriyetlerinde faaliyetlerde bulunan İran, Şiîlik düşüncesini bu bölgede yayma çabası içerisindedir. Özellikle aşırı Şiî mezheplerden olan ve Tacikistan Bedahşan ve Fergana Vadisi'nde yerleşik düzeni bulunun Şiîİsmailî mezhebi, kendi felsefesini ihraç etme gayretindedir. $\mathrm{Bu}$ ve benzeri mezheplerde "takiyye" bir esas olduğu için, duygu ve düşüncelerinin tamamen aksi istikamette söylem ve eylemlerde bulunarak, inançlarını yaygınlaştırma çabasındadırlar (Abaşin 2001: 272).

Orta Asya Türk Cumhuriyetlerinde İran'ın etkisinin anlaşılması için öncelikle Azerbaycan'a bakmak gerekir. Azerbaycan'da İslam'ın geniş alanlarda yayılması özgürlüğün ilk yıllarında baş göstermiştir. Özgürlüğünü 
elde ettiği 1991 yllında diğer Türk Cumhuriyetlerinde olduğu gibi Azerbaycan'a birçok Arap ülkesi ile birlikte, komşu İran ve Türkiye'den de İslamî cemaatlerin gelişi başlamıştır. $\mathrm{Bu}$ da haliyle Azerbaycan nüfusunun İslam konusunda bilgilenmesine, ardından ise Müslümanlar arasında siyasî bir görüşün oluşmasına yol açmıştır. Şu an Azerbaycan'da her ne kadar suyun yüzeyinde patlama yapmamış olsa da, İran'ın din ve mezhep faktörünü kullanarak ülkenin iç politikasına müdahale tehlikesi vardır. Çünkü Azerbaycan'daki Şî̂ Müslümanların ekserisi İranlı müçtehitlerin verdikleri fetvaları tatbik etmektedirler. Tüm bunlardan daha tehlikelisi ise, mezhebî yönden İran'a bağlı bazı Şiî Müslümanların, Azerbaycan Devleti aleyhinde bir düşünce yapısına sahip olmalarıdır. Buna göre, Azerbaycan İran'ın tarihi topraklarından biridir ve er veya geç İran'a dâhil edilmelidir (Hafizoğlu 2010).

Orta Asya'da din ve dinî radikalizmin gündeme gelmesindeki bir başka etken de, Sovyetler Birliği'nin İslam'a karş1 yürüttüğü uzun süreli mücadeleye rağmen, 1980 ve 90'lı yllarda Orta Asya'da yeniden yeşeren 'İslamî Diriliş' şeklinde adlandırılan dinî canlanma, öncelikle gelenekselcilikten kaynaklanmaktadır. Buna göre güncel dinî gelişme, 19 Yüzyıldaki oluşumun yeniden dönüşünü simgelemektedir. Bu gelişim aynı zamanda farklı bir ivme kazanarak, daha radikal ve bir tür öze dönüş şeklinde tezahür etmiştir. Sonuç ister gelenekselcilik isterse de öze dönüşüm olsun, realite dinî bir gelişim şeklindedir. Bunun ana etkeni ise, Sovyetler Birliği'ndeki ekonomik başarısızlık ve yeni kurulan devletlerin de bir şekilde bu olumsuz tabloyu yansıtmalarıdır. $\mathrm{Bu}$ ise, insanların yeni çözümler arayışına yol açmaktadır (Baycaun 2001, 84-85).

Orta Asya'da dinî gelişmelerin yaşanması yanında radikal oluşumların dikkat çekmesinin farklı bir gerekçesi de, Sovyetler Birliği döneminde komünizm ve sosyalizm gibi bir takım idealler etrafında yetiştirilen nesiller, bu dönemin çöküşünden sonra ideallik ruhunu farklı bağlamlarda devam ettirmeleridir. Bu alanda en köklü ve alışılmış hedef din olmuştur. $\mathrm{Bu}$ ise belirli kesimlerin dini alandan idealist yetişmesine ve sosyo-ekonomik şartlar doğrultusunda radikalleşmesine yol açmıştır (Peker, 1996: 79).

Ortaasya'da şekillenen bu oluşumun, Balkanlarda da gerçekleştiğini görmek gerekir (Shay 2007: 208-209). Aynı radikal dini guruplar, benzer metotları Balkanlar'da yaşayan Müslüman Türklerin bulundukları yörelerde de uygulamaktadırlar (Dalkılıç, Biçer, Demirli 2012).

\section{Değerlendirme ve Sonuç}

Orta Asya Türk Cumhuriyetlerinde, İslamî temalı dini hareketlerin kaynağı, Orta Doğu kökenli radikal din akımlardır. Bunların başında Selefi-Vehhabi anlayış 
ve temayül gelmektedir. $\mathrm{Bu}$ oluşumun arka planını okumak gerekirse, karşımıza şu tablo çıkmaktadır:

1. Sovyetler Birliği sonrası bağımsızlık kazanan Türk Cumhuriyetlerinde veya Rusya Federasyonunda bulunan Türk halklarını bekleyen en öncelikli dinî tehlike, Hıristiyan misyonerlik faaliyetleridir. Bu faaliyetler başta Rusya olmak üzere ABD ve Batı devletlerinin resmî destek ve teşvikiyle gerçekleşmektedir. Bunun yanında 2000 yılı itibarıyla üç binden fazla mezhep ve tarikata sahip olan Hıristiyanlık kilisesi ve SKT'lar yanında gizli çalışmaların varlığı dikkate alındığında, sorunun büyüklüğü anlaşılabilir.

2. Bir başka misyonerlik faaliyeti olarak değerlendirilebilecek hareket ise, Budizm felsefesi yanında Yeni Çağ Dini akımlardır. Çeşitli spor, felsefe öğretimi ve sağlık kuruluşları şeklinde faaliyette bulunan ve çoğu gizli olan bu sekt ve kültler, yöre halklarını yönlendirmektedir.

3. Bölgede üçüncü derecede kökü dışarıda faaliyette bulunan akımlar ise, Orta Doğu kökenli İslamî temalı dinî hareketlerdir.

Bu problemler karşısındaki çözüm önerileri şöyle sıralanabilir:

Türkiye modeli ve ülke şartları doğrultusunda dinî ihtiyaçları karşılamaya yönelik İlahiyat Fakültelerinin açılması. Ayrıca geneli itibarıyla Sünnî-Hanefî Matüridî olan halkların inanç sistemlerini temellendiren ve bilgilendiren Matüridî mezhebine yönelik bilimsel çalışmaların artırılması. Öte yandan bölgede hâkim olan Nakşibendîlik ve Yesevilik gibi tasavvufî akımların sağlıklı bir yapıda ve siyasetten uzak bir konumda işlenmesi ve bilimsel boyutta halka yönelik değerlendirilmesi de gözden irak tutulmayarak işler hale getirilmesi. Böylece yüzyıllardır Rus egemenliğine karşı konulmada önemli bir faktör olması açısından, hem tarihsel arka planı dolayısıyla gelenek dikkate alındığı gibi, farklı bir tasavvufi anlayışa sahip olan ve Orta Asya'da İsmaililik gibi aşırı uçları da güçlü olan Şiîlik akımının gelişmesine de set çekilmiş olacaktır.

Bölge istikrarında önemli bir paya sahip olan ekonomik oluşum, belirli bir düzeye ulaşması gerekmektedir. İktidarlar, halkının geçim sıkıntısını gidermek, eğitim ve sağlıkta belli bir düzeye ulaşmak amacında olmalıdır. $\mathrm{Bu}$ gerçekleştirilmezse, iktisadî bunalımda olup, fakirlikle didişen halk, alternatif çözümler arayarak radikal akımlara temayül etmekten vazgeçebilir. Bunun farklı bir sonucu da iktidarlar, başarısızlıklarını sürekli radikal akımların mevcudiyetinden bahsetmekle örtmek amacından vazgeçmesi gerekir.

Her an yaşanması muhtemel krizin önüne geçmek için ise, Türk Cumhuriyetlerinde en kısa zamanda yerel/yerli dinî kadroların ve dinî siyasetin geliştirilmesi gerekmektedir. 


\section{Kaynaklar}

Abaşin, Sergey N. (2001). "Orta Asya Kökten Dinciliğinin Kökenleri Hakkında Birkaç Söz”. Çev. Saule Baitzhaunova-Nermin Guliyeva, Avrasya Dosyasi, VI (4): 272-282.

Aydın, Mustafa (1996). "Identities in Formation; Nationality, Religion and Transnational Ideas in Former Soviet Asia". The Turkish Yearbook of International Relations. XXVI. 65-79.

Baycaun, Saule (2001). “Orta Asya ve Özbekistan'da İslam ve Köktendincilik". Avrasya Dosyası VII (3): 81-101.

Bicer, Ramazan (2006). Religious Understanding of Turkish and Pakistani People. Ethics, Values and Society: Social Transformation. ed. Ghazala Irfan. Oxford: Oxford University Press, 273-283.

Bicer, Ramazan (2009a). Jihad is a Sacred Terror? Actas Del IX Congreso 'Cultura Europea'. Spain: Thomson Reuters, 929-943.

Bicer, Ramazan (2009b).The Approach of Muslim Turkish People To Religious Terror. The World's Religions after September 11. Volume 1, Religion, War, and Peace (ed. Arvind Sharme). USA: Greenwood Publishing, 87-114.

Büyükkara, M. Ali (2004). Ihvan'dan Cüveyman'a Suudi Arabistan ve Vahhabilik. Istanbul: Ragbet Yayinlari.

Dalkılıç-Biçer-Demirli (2012). Balkanlarda Dini Aşırılıklar ve Etnik Barış. İstanbul: Tasam Yayınları.

Davlatov, Timur B. (2006). “Orta Asya'da Dini Ekstremizm Yaygınlaşabilir mi?’. Hacettepe: Türkiyat Araştırmaları. III (4): 177-184.

Ebu Zahra, Muhammed (1977). Tarihu'l-Mezahibi'l-Islamiyye. Kahire: Daru'l-Fikri'l-Arabi.

Ecer, A. Vehbi (1996). Osmanll Tarihinde Vehhabi Hareketi. Ankara Üniversitesi İlahiyat Fakültesi, Doktora tezi.

Emin, Ahmed (1954). Yevmü'l-İslam. Kahire: Mektebetü'l-Hanci.

Erdem, Mustafa (2004). "Orta Asya Güvenliğinde Radika Dini Hareketler Sorunu”, Stratejik Analiz. IV (46): 79-87.

Erşahin, Seyfettin (1998). "Bağımsızlık Sonrası Türk Cumhuriyetlerinde Dini Yapılanma”. Türk Dünyasında Dini Meseleler Sempozyumu. Ankara. 25-58.

Erşahin, Seyfettin (2004). "Orta Asya Türk Cumhuriyetlerinde Ulusal Güvenlik ve Din”. Dini Araştırmalar, VII (20): 179-194.

Fıglalı, Ethem Ruhi (1999). Çă̆ımızda Ittikadi İslam Mezhepleri. X. Baskı, İstanbul: Birlesik Yayınları.

Hafizoğlu, Rufiz (2010). Azerbaycan Din Kriziyle Baş Başa. TASAM. www.tasam.org. (14.04.2010) 
Hellmich, Christina (2008). "Creating the Ideology of Al Qaeda: From Hypocrites to Salafi-Jihadists”. Studies in Conflict \& Terrorism.

Keskin, Abdülbaki (1996). I. Avrasya Íslam Şurası, Ankara: Diyanet İşleri Başkanlığı Yayınları.

Peker, Günden (1996). "İslamiyet Orta Asya'da Mit mi Gerçek mi?". Avrasya Etütleri, III (3): 73-83.

Rashid, Ahmad (2002). Jihad: The Rise of Militant Islam in Central Asia. Yale.

Shay, S. (2007). Islamic Terror and the Balkans. London: Transaction Publishers.

Topaloğlu, Bekir (2004). Kelam İlmi: Giriş. İstanbul: Damla yayınevi.

Uysal, Veysel (1996). Din psikolojisi açısından dini tutum davranış ve şahsiyet özellikleri. İstanbul: Marmara Üniversitesi İlahiyat Fakültesi Vakfi.

Wiktorowicz, Quintan (2006). "Anatomy of the Salafi Movement". Studies in Conflict \& Terrorism. XXIX (): 207-239.

Yönem, Ahmet (2005). Horasan-Maveraünnehr Bölgesine Haricilik. Ankara: Ankara Üniversitesi İlahiat Fakültesi (Doktora tezi). 